\title{
An Algorithm to Determine Airport Runway Usage/Configuration Based on Aircraft Trajectories
}

\author{
Raúl Torres*, Pedro C. Álvarez-Esteban*, Nicolas Peña ${ }^{\dagger}$ \\ * Instituto de Investigación en Matemáticas (IMUVA) and Dpto. de Estadística e Investigación Operativa, \\ Universidad de Valladolid, 47011, Valladolid, Spain \\ Email: \{raulandres.torres, pedrocesar.alvarez\}@uva.es \\ $\dagger$ Boeing Research \& Technology Europe, 28042, Madrid, Spain \\ Email: nicolas.penaortiz@boeing.com
}

\begin{abstract}
Air transportation growth is a reality described by different sources (e.g. The World Bank [1], the latest Eurocontrol report [2]). One essential initiative required to improve air traffic capacity while maintaining or increasing safety is to introduce predictive analytics that enable a dynamic adaptation of airline operations in a preemptive manner to an ever changing environment. An important part of this task is to model airport operations and plan accordingly. Particularly runway usage and/or configuration are important aspects of these operations. For example, prior knowledge of runway usage could improve flight plan optimizers. Of course, to create any model or predictor, ground truth data is required. However most of the time, detailed information about runway historical usage/configuration is inaccessible, unreliable or it belongs to national ATC services providers. Then, thinking on a high-scale forecast methodology there is an important drawback given the lack of a feasible target for most of the airports. Thus, the goal of this work is to introduce an accessible, easy to implement algorithm that allows historical reconstruction of runway usage/configuration for any airport based on data transmitted from aircrafts through either Radar or ADS-B technologies, even when the track data is not consistent. We study the quality of the assessment performed by the two parts of the algorithm: 1) Measuring the flight usage accuracy in comparison to the report given by the Spanish ATC service provider (ENAIRE) for each flight landing to or takingoff from two Spanish airports, Madrid-Barajas and BarcelonaEl Prat, during October 2016. 2) Comparing the NetherlandsSchiphol runway configuration reported by the Netherlands airspace regulator (LVNL) for three different months, February, April and August 2018. The results provide values above $97 \%$ of accuracy for both types of assessment.
\end{abstract}

Index Terms-Runway usage, airport runway configuration, ADS-B technology, take-off, landing.

\section{INTRODUCTION}

Air transportation has grown exponentially in the last decades (see, e.g., the time series of carried passengers published by The World Bank [1]), and the forecasts predict that this growth will continue in the foreseeable future. Focusing in Europe, the forecast of the latest report of Eurocontrol [2] points out 12.7 million of flight movements in the European airspace by 2025 , which is an increment of $15.2 \%$ over 2018 levels. The Single European Sky (SES) and the Next Generation Air Transportation System (NextGen) initiatives, in Europe and
USA respectively, were born to handle this growing problem and accommodate the increasing air traffic, while improving its performance, reducing costs, and having a more safer and an environmentally responsible air transportation system.

Airport operations are one of the key points in the search of greater efficiency and better performance in the air transportation system, and part of these operations are influenced by runway usage/configuration. The responsibility to perform a proper runway configuration is entirely up to tower and air traffic controllers at the airport. Examples to show the benefits of the knowledge of this information in advance are the reduction of time flight and the improvements of associated taxi times given a more precise knowledge of the potential SID and STAR procedures at flight planning. Further optimizations are the calculation of fuel requirements and ETA.

Thus, a scientific interest to help controllers with the task of establishing accurate runway configurations, as well as other developments directly or indirectly related to runway usage has been growing in recent years: a runway scheduling optimization (see, e.g., [3], [4]), forecast of runway configurations taking into account several factors as weather forecasts and others (see, e.g., [5], [6]), forecast of runway capacity (see [7], [8]), impact of runway configuration on arrival delays ([9]), taxi-times prediction ([10]), noise load on the proximity of an airport ([11]), etc...

However, most of the time the information of historical airports runway usage/configuration is not public; it is inaccessible, unreliable or it belongs to national ATC services providers. Therefore, it is of great interest to the research community to have a public algorithm, accessible and easy to implement, that provides this information for any airport from available data sources including those providing either Radar or ADS-B data. Moreover, this type of algorithm is also essential for validation purposes on any prediction model of airport runway configuration.

The Netherlands-Schiphol airport is one of the few publishing runway configurations (see https://en.lvnl.nl/ environment/runway-use) and this fact joint to its complexity make it a case study for some works in the literature. We also 
use it to validate the runway configuration assessment given by our algorithm. On the other hand, we use data of flights landing and taking-off from Madrid-Barajas and Barcelona-El Prat airports, provided by the Spanish ATC services (ENAIRE), to validate the runway usage assessment.

Thus, the structure of the paper is as follows: Section II describes the algorithm of airport runway usage and the extension to obtain associated runway configurations. In Section III shows the results of the algorithm for both cases, usage and configuration. Section IV concludes the document and presents some future lines of research. Finally, Appendix summarizes some cases that generate the rejection of information inside the algorithm to prevent misclassifications.

\section{RUNWAY USAGE ALGORITHM AND RUNWAY CONFIGURATION ASSESSMENT}

The goal of this work is to describe an algorithm that allows the users to reconstruct airport runway usage and also runway configuration. A proposal for this algorithm is detailed in this section. As it was mentioned in Section I, information about airport runway usage/configuration is confidential and/or unreliable. However, we aim to reconstruct this information based on three important data sets: 1) Data of airports worldwide including its ICAO code and location (latitude, longitude), 2) Data of the runways at each airport including runway labels, latitude and longitude describing their polygons, 3) Historical flight information transmitted by ADS-B (or RADAR) technology providing time, location and altitude of the aircrafts (e.g. see the data lake described in $\left.[12]^{1}\right)$. With these three databases, we perform a reconstruction of flight trajectories and the assessment of airport runway usage.

First, we focus on the task of runway usage assessment. The parameters required to start this task are the ICAO code of the airport of interest and a time window for the analysis of flight trajectories. Thus, the algorithm bases on two aspects to perform assessments: 1) the altitude variation of the aircraft, which provides the decision of type of usage (take-off or landing) and 2) proximity and alignment to the runways at the airport, to determine the runway linked to each aircraft trajectory. Finally, using these two parts the runway label associated with each flight is determined.

We also highlight that there exist some parameters used in the algorithm to define boundaries and improve results. The selection of values for these parameters have been established through heuristics, e.g. the aircraft trajectories considered are those overflying the airspace around the airport under the $4500 \mathrm{ft}$. To reconstruct the flight trajectory some registers are dropped. Thus, we define the minimum and the maximum number of recorded location transmissions for each flight sorted by time as 4 and 11, respectively. The former is fixed, while the latter remains as a modifiable argument.

Now, we describe the procedure of runway usage assessment in three parts. Firstly, we detail the process of type of

\footnotetext{
${ }^{1}$ This data lake includes ADS-B data from Fligthradar24 and other providers.
}

usage, which is priorly performed according to the altitude variation across the aircraft trajectory. The inference of this type of usage is based on a weighted result between three possibilities described in decreasing order of weight. 1) a robust linear regression of altitude vs. time, 2) a classical linear regression of these variables and 3) the difference between the first and the last registers of the trajectory. The previous structure of decision making is required due to causes such as last minute land canceling, transponder errors, etc.

Secondly, different cases are analyzed to determine the used runway. These cases require the following definitions and formulations, (we use Schiphol airport for illustrative purposes).

Proximity: defined as the closest distance between registered locations of the aircraft and points on the grids describing the runways at the airport. The proximity conditions used in the algorithm are boundaries determined based on unit variations in a decimal place of latitude or longitude at the equator. For instance, a condition of 110 meters is the approximate distance varying 1 unit in the third decimal place of latitude or longitude at the equator.

Mean angle of alignment: it refers to the mean of the angles between segments of the aircraft trajectory and the lateral segment of a runway.

Artificial angle: It is the angle generated between the lateral segment of a runway and the artificial segment defined between the closest point of the runway to the initial or last (for take-offs or arrivals respectively) reported position of the aircraft.

Figure 1(A) displays a runway representation that help us to describe the lateral segments and Figure 1(B) describes a classical trajectory of an aircraft by segments according to the transmitted Radar or ADS-B location. Therefore, it is possible to determine the mean angle of alignment as the mean of all the angles obtained by,

$$
\begin{aligned}
r w S e g= & \left(r w_{2, l o n}-r w_{1, l o n}, r w_{2, l a t}-r w_{1, l a t}\right), \\
\operatorname{trajSeg}_{j}= & \left(x_{j+1, \text { lon }}-x_{j, l o n}, x_{j+1, l a t}-x_{j, l a t}\right), \\
& j=1, \ldots, \text { min }(\text { number of registers }-1,10), \\
\theta_{j}= & \arccos \left(\left|\frac{r w S e g^{T} \cdot \text { trajSeg }_{j}}{\| \text { rwSeg } \||| \text { trajSeg }_{j} \|}\right|\right),
\end{aligned}
$$

where $\left(r w_{i, l o n}, r w_{i, l a t}\right), i=1, \ldots, 4$ are the longitude and latitude georeferences of the runway and $\left(x_{j, l o n}, x_{j, l a t}\right)$ are the reported longitude and latitude positions by either Radar or ADS-B transmissions. Notice that $r w S e g$ can also be defined by the difference of the georeferences 3 and 4 without any further implication. The only warning to be aware is that we do not mix georeferences missing the true lateral segment of the runway. Now, we summarize the analyzed cases of proximity and alignment.

Case 1 (Proximity under 110 meters): The ADS-B signals are frequently initiated after the take-off or stopped before the landing, but there are occasions where the signals are 


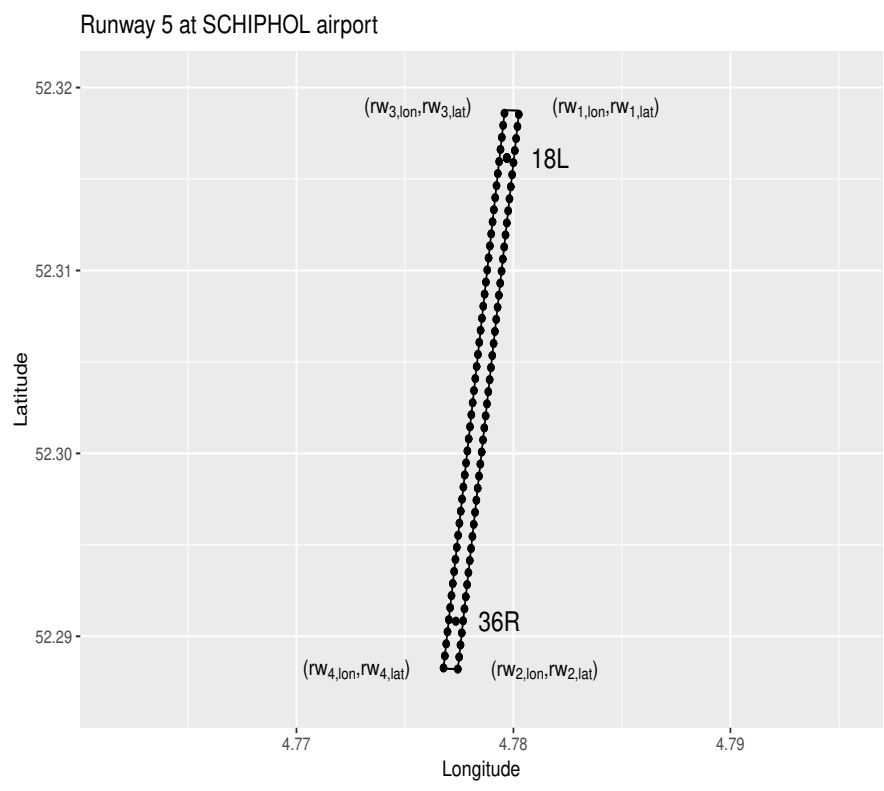

(A) Runway representation

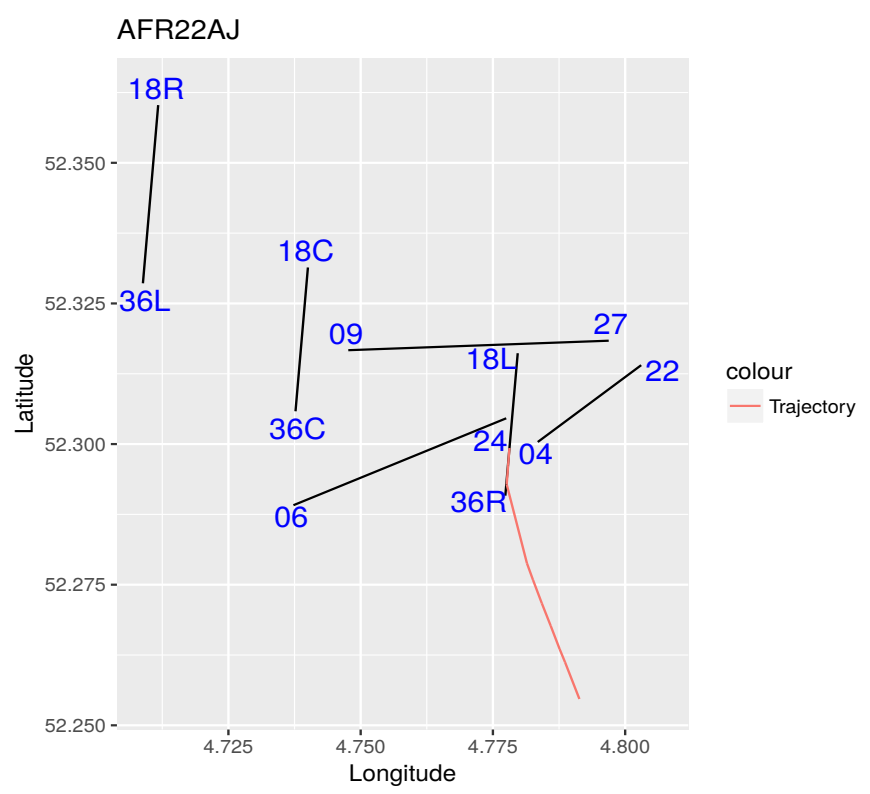

(B) Aircraft trajectory

Fig. 1. Runways standard representation and aircrafts trajectories by polygonals

transmitted from the ground and the identification of the used runway is transparent.

Case 2 (Proximity between 110 meters and 1.5 kilometers and alignment): Now, for flights registering proximity no longer than $1.5 \mathrm{~km}$, we proceed to analyze the mean angle between the segments of the trajectory and the lateral segments of the runways. For those runways that generate a mean angle lower that 15 degrees with the given trajectory, we establish the set of parallel runways (if there is any). Then, we proceed to determine the runway by selecting the one providing the minimum artificial angle.

In this proximity case, when the condition of 15 degrees of alignment is not satisfied, an extra condition arises. Then, for the nearest runway and its parallels, it is analyzed the minimum artificial angle and if there is an angle lower than all the measured mean angles and also lower than 30 degrees, then the corresponding runway is selected as the used runway. Otherwise the best fit is reported with status 0 to be latter summarized as discarded.

Case 3 (Proximity between 1.5 kilometers and 3 kilometers and alignment): This case considers distances between $1.5 \mathrm{~km}$ and $3 \mathrm{~km}$, but this implies the need of good alignment far from the runways. However, it not always occurs considering the mean angles between the aircraft trajectories and the lateral segments of the runways, particularly when take-offs are analyzed. This fact provides more importance to the artificial angle, then the selection is done as the runway holding to be simultaneously the one providing minimum distance and the one with minimum artificial angle, being the last one lower than the mean angle and lower than 30 degrees. In other case, the runway that fits better is selected but marked with status 0 .

Case 4 (Assessment but status 0): The last case assesses all the trajectories being farther than $3 \mathrm{~km}$ based only on the alignment, i.e., the analysis of the trajectory and artificial angles, but all these cases are marked with status 0 because these trajectories are not reliable to conclude. Therefore, such cases are summarized as discarded at the end of the procedure.

Thirdly, we have to assess which side of the runway was used. For instance, for a runway with routes labeled $18 \mathrm{~L}$ and 36R as in Figure 1(A), which of those labels should be reported? To perform this final assessment, we construct a grid on the selected runway classifying half of the runway as $18 \mathrm{~L}$ (red dots) and the other half as 36R (blue dots) (see Figure 2). Then, we calculate the distances between each of the trajectory positions and the runway grid to obtain a pool of distances labeled with $18 \mathrm{~L}$ and other with 36R. Now, if for instance we have previously determined a landing operation, then the label associated with each position is the label having a maximum mean distance. Finally, the decision of the runway label for the full trajectory is based on the biggest weighted average by label, giving more weight to the earlier registers of the trajectory than the last ones. On the other hand, for the take-off case, the label for each position is given by the one holding the minimum mean distance and the averaging weights are distributed at the contrary.

Thus, a pseudo-algorithm can be described as follows:

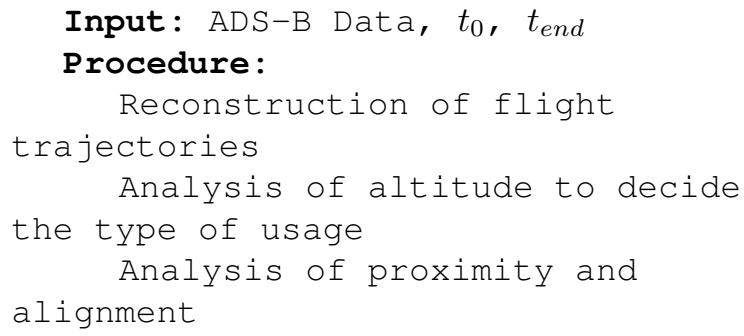




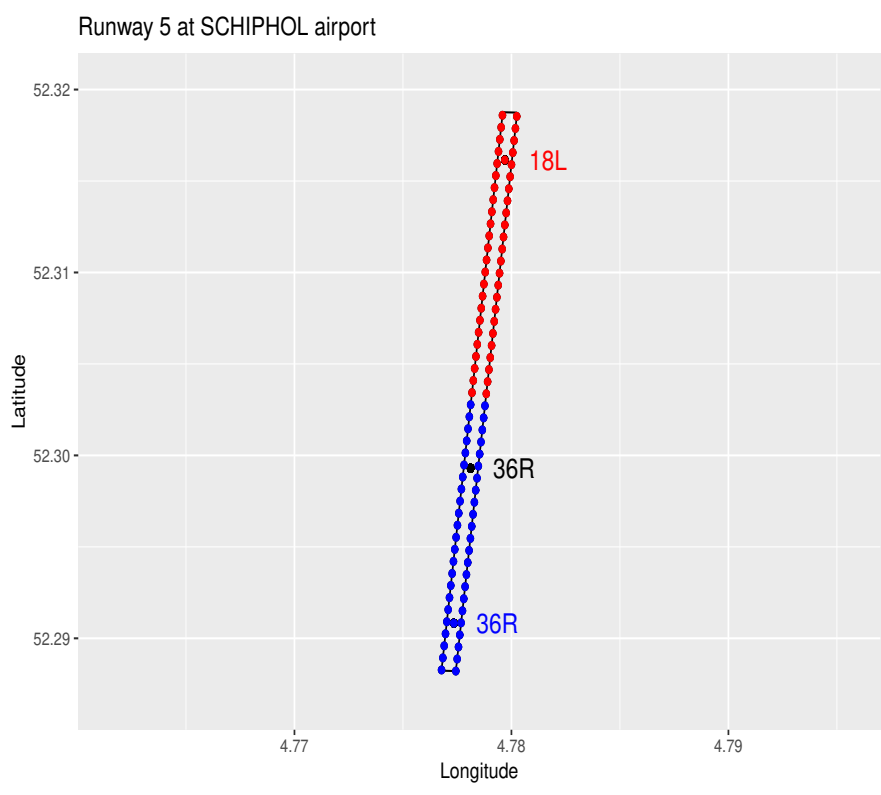

Fig. 2. Runway grid and division for the classification of usage type

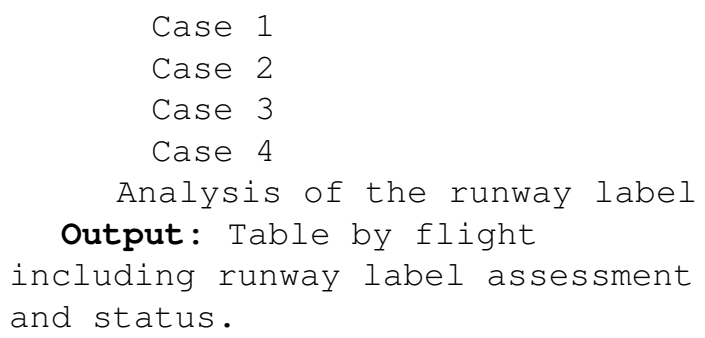

Later in the Appendix, we summarize special cases that the algorithm discards when they are correctly assessed or the algorithm accepts when the assignment is wrong. Now, we focus on the task of airport runway configuration. In general, runway configuration changes eventually in response to climatology and other factors such as density of flights. Then, the configuration results are valid just for fixed time windows.

The task can be completed by considering a time-window parameter (for instance of 30 minutes), and two corrections to avoid misclassifications of usage and overlapping of configuration changes. Thus, robust statistics analysis is performed on the results of historical runway usage to generate the most reliable set of runway combinations out of those taking landings and take-offs during each time-window present across the historical data.

Notice that the number of combinations that one can consider as a possible configuration grows exponentially with the number of runways at the airport. Then, based on frequency quantiles, we describe the configuration sets at the airport of interest and after, we prevent the possibility of those sets having risky combinations such as opposite directions of a runway hosting opposite operations, or the same direction of a runway hosting opposite operations where there are parallel and operative runways.

This twofold construction provides the optimal set of possible configurations and finally, the associated runway configuration for each time-window can be selected as the closest configuration to the one reported by the summary of results provided by the runway usage algorithm.

\section{RESUlTS AND VALIDATION}

The output of the runway usage algorithm is a table by flight registering the determined runway label and the acceptance or discarded decision in a status field. A summary of those assessments can be done by status. Table I is an example of the summary for the case study at Schiphol Airport (EHAM) between 12:00 and 13:00 hours of June 19, 2018. It can be seen all the runway labels and the types of usage (landing or take-off) in absolute and relative terms. Similarly, Table II summarizes the results of discarded data for the same case study. From the summary in Table I, one could say that Schiphol's airport configuration in the given time window is runways $18 \mathrm{C}$ and $18 \mathrm{R}$ for landings and 24 and $18 \mathrm{~L}$ for takeoffs.

\begin{tabular}{||c||c|c|c|c||}
\hline \hline Runway & Landing & Take.Off & \%Landing & \% Take.Off \\
\hline \hline RW04 & 0 & 0 & 0.00 & 0.00 \\
\hline RW22 & 0 & 2 & 0.00 & 2.53 \\
\hline RW06 & 0 & 0 & 0.00 & 0.00 \\
\hline RW24 & 0 & 40 & 0.00 & 50.63 \\
\hline RW09 & 0 & 0 & 0.00 & 0.00 \\
\hline RW27 & 0 & 0 & 0.00 & 0.00 \\
\hline RW18C & 24 & 0 & 32.43 & 0.00 \\
\hline RW36C & 0 & 0 & 0.00 & 0.00 \\
\hline RW18L & 0 & 37 & 0.00 & 46.84 \\
\hline RW36R & 0 & 0 & 0.00 & 0.00 \\
\hline RW18R & 50 & 0 & 67.57 & 0.00 \\
\hline RW36L & 0 & 0 & 0.00 & 0.00 \\
\hline \hline
\end{tabular}

TABLE I

SCHIPHOL AIRPORT RUNWAY USAGE BETWEEN 12 AND 13 HOURS AT JUNE 19, 2018

\begin{tabular}{||c||c|c|c|c||}
\hline \hline Runway & Landing & Take.Off & \%Landing & \% Take.Off \\
\hline \hline RW04 & 0 & 0 & 0.00 & 0.00 \\
\hline RW22 & 0 & 0 & 0.00 & 2.53 \\
\hline RW06 & 0 & 0 & 0.00 & 0.00 \\
\hline RW24 & 0 & 1 & 0.00 & 16.67 \\
\hline RW09 & 0 & 0 & 0.00 & 0.00 \\
\hline RW27 & 0 & 1 & 0.00 & 16.67 \\
\hline RW18C & 1 & 0 & 50.00 & 0.00 \\
\hline RW36C & 0 & 0 & 0.00 & 0.00 \\
\hline RW18L & 1 & 4 & 50.00 & 66.67 \\
\hline RW36R & 0 & 0 & 0.00 & 0.00 \\
\hline RW18R & 0 & 0 & 0.00 & 0.00 \\
\hline RW36L & 0 & 0 & 0.00 & 0.00 \\
\hline \hline
\end{tabular}

TABLE II

SCHIPHOL SUMMARY OF DISCARDED FLIGTHS BETWEEN 12 AND 13 HOURS AT JUNE 19, 2018

A graphical exploration of the results can be seen in Figure 3(A), where it is shown the aircraft trajectory of a landing runway usage at the airport and Figure 3(B) shows the analogous for a take-off usage, both of them highlighting the runway label selected by the algorithm. 


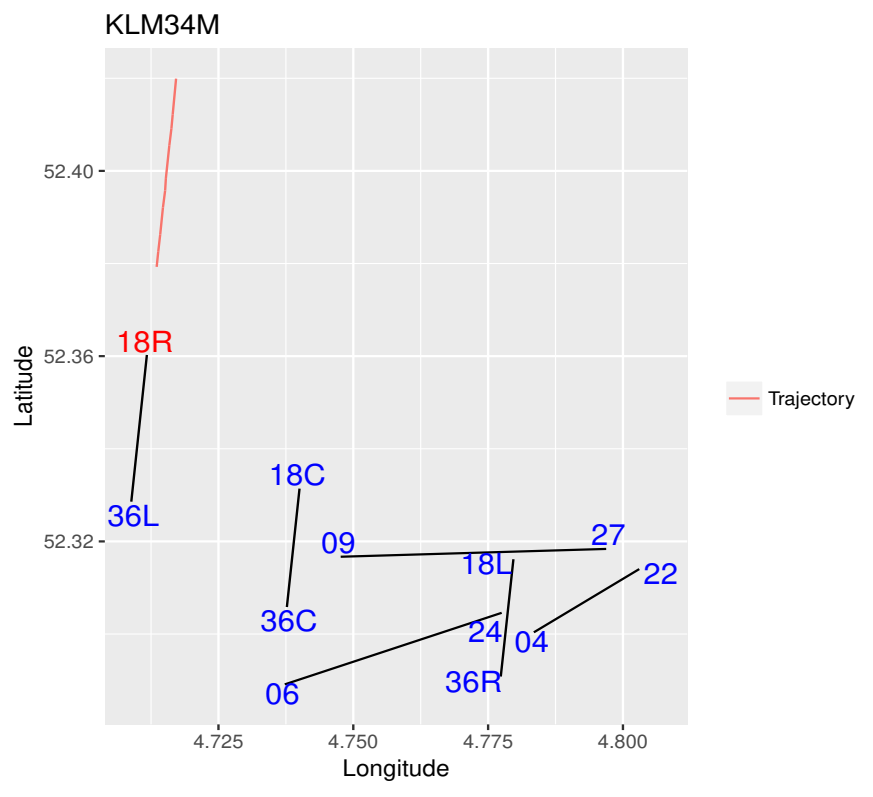

(A) Landing in the $18 \mathrm{R}$ route

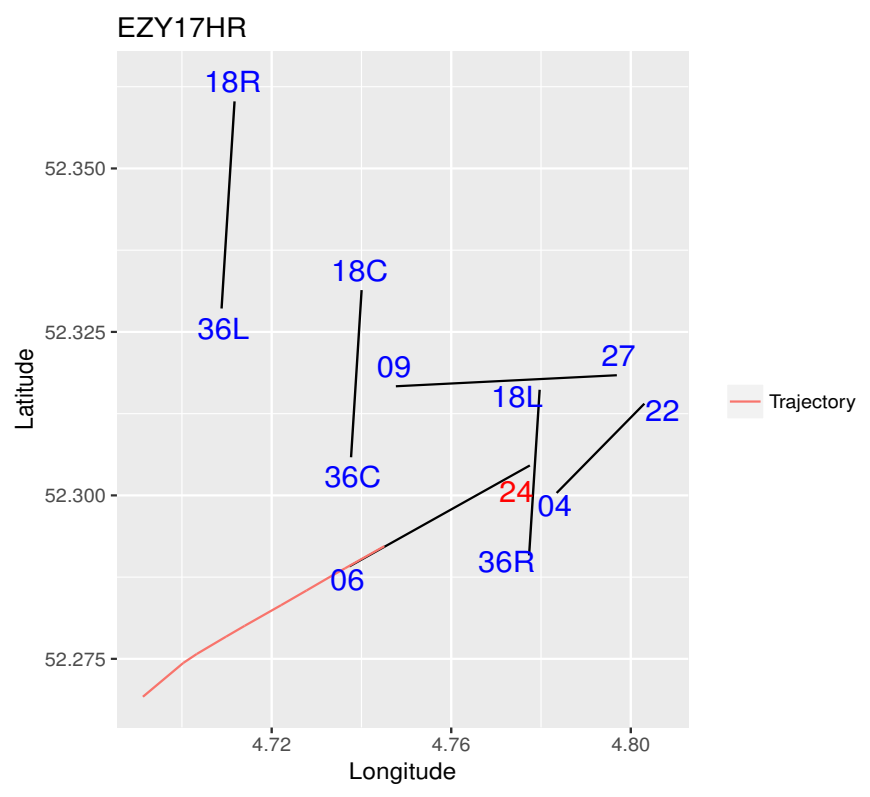

(B) Take-off using the 24 route

Fig. 3. Examples of aircrafts trajectories and runways usage at Schiphol airport

Finally, it is performed a validation for both of the assessments, used runways and airport configurations, in comparison to data of its own nature. First, we compare the results of runway usage with data from the Spanish ATC services provider (ENAIRE). Second, we compare the results of the runway configuration procedure against Schiphol's airport configuration reported by the Netherlands airspace regulator (LVNL).

In the first case, ENAIRE provided us reports of the used runways for all the flights landing or taking-off from Spanish airports in October 2016. Then, we evaluate the accuracy of the algorithm at two different airports Madrid-Barajas and Barcelona-El Prat, whose ICAO codes are LEBL and LEMD respectively. The results are shown in Table III, where it can be seen the high accuracy of the algorithm. LEBL airport has the highest rate of discarded flights between the two airports with $17.5 \%$ out of 23446 flight trajectories, but also higher performance assessing the remaining trajectories with $99.5 \%$.

\begin{tabular}{||c||c|c|c|c||}
\hline \hline Airport & $\begin{array}{c}\text { \%Accuracy on } \\
\text { valid flights }\end{array}$ & $\begin{array}{c}\text { \%Failure on } \\
\text { valid flights }\end{array}$ & \%Discarded & $\begin{array}{c}\text { Total Num. } \\
\text { of Fligths }\end{array}$ \\
\hline \hline LEBL & 99.5 & 0.5 & 17.5 & 23446 \\
\hline LEMD & 98.8 & 1.2 & 6.6 & 20640 \\
\hline \hline
\end{tabular}

TABLE III

VALIDATION AIRPORT RUNWAY USAGE THROUGH ENAIRE DATA

On the other hand, LVNL reports in its website the airport configuration every 5 minutes. Then, we have taken this information for three different months (February, April and August 2018). Table IV summarizes the set of most frequent runway configurations at Schiphol among these three months and the median time of duration of each runway configuration.

\begin{tabular}{||c|c|c||}
\hline \hline Landing Rwy. Cfg. - Take.Off Rwy. Cfg. & \% freq. & Median Time(min) \\
\hline \hline 06 - 36L & 10.03 & 85.00 \\
\hline 18R - 18L 24 & 9.61 & 56.98 \\
\hline 06 - 36C 36L & 7.93 & 52.25 \\
\hline $18 \mathrm{R}-24$ & 7.75 & 60.00 \\
\hline 06 36R - 36L & 6.91 & 54.00 \\
\hline 06 36R - 36C 36L & 6.77 & 45.00 \\
\hline 18C 18R - 18L 24 & 6.31 & 47.75 \\
\hline 18C 18R - 24 & 3.72 & 67.00 \\
\hline 27 - 24 36L & 2.26 & 60.00 \\
\hline 18C - 18L 24 & 2.22 & 59.50 \\
\hline 18C - 24 & 2.06 & 105.00 \\
\hline 06 - 09 36L & 1.94 & 50.00 \\
\hline 36R - 36C 36L & 1.80 & 60.50 \\
\hline 18C 18R - 18L & 1.76 & 81.50 \\
\hline 36C 36R - 36L & 1.70 & 50.00 \\
\hline \multicolumn{2}{|c|}{}
\end{tabular}

TABLE IV

SCHIPHOL AIRPORT RUNWAY CONFIGURATIONS REPORTED BY LVNL

Now, considering the detected changes of configuration and their corresponding time-windows, we perform the configuration assessment. Recall that this task is done considering a feasible set of configurations such as those reported in Table IV. However, we obtain the feasible set of configurations applying the method described at the end of Section II, given the data-driven and massive structure that we want to present. Then, Table $\mathrm{V}$ summarizes the most frequent runway configurations based on the recovered runway usage history in time-windows of 30 minutes between July 1, 2017 and June 30, 2018.

Then, using that feasible set of runway configurations, we continue the process and we evaluate its accuracy taking into consideration that the assessment is correct if the reported configuration is contained in the algorithm results or viceversa. The results of the validation process are summarized in Table VI and one can appreciate also high rates of accuracy over $97.0 \%$ and up to $99.2 \%$, which provides consistency to both 


\begin{tabular}{|c|c|}
\hline Landing Rwy. Cfg. - Take.Off Rwy. Cfg. & $\%$ freq. \\
\hline $18 \mathrm{C} 18 \mathrm{R}-2224$ & 9.93 \\
\hline $18 \mathrm{C} 18 \mathrm{R}-18 \mathrm{~L} 2224$ & 8.93 \\
\hline $18 \mathrm{C}-18 \mathrm{~L} 2224$ & 6.37 \\
\hline $0406-36 \mathrm{C} \mathrm{36L}$ & 6.35 \\
\hline $06-36 \mathrm{C} \mathrm{36L}$ & 5.39 \\
\hline 18C 18L 18R - 2224 & 3.73 \\
\hline 06 36R - 36C 36L & 3.17 \\
\hline 18C 18R - 18L & 2.89 \\
\hline $18 \mathrm{R}-18 \mathrm{~L} 2224$ & 2.44 \\
\hline $18 \mathrm{R}-2224$ & 2.38 \\
\hline 0406 36R - 36C 36L & 2.36 \\
\hline $27-222436 \mathrm{C} 36 \mathrm{~L}$ & 2.13 \\
\hline $06-36 \mathrm{~L}$ & 2.04 \\
\hline 18C 18L 18R - 092224 & 1.90 \\
\hline $0406-09$ & 1.87 \\
\hline 18C 18R - 0609 & 1.70 \\
\hline
\end{tabular}

TABLE V

SCHIPHOL AIRPORT RUNWAY CONFIGURATIONS OBTAINED THROUGH THE ALGORITHM

goals, runway usage and runway configuration reconstruction, considering the different data sources and airports.

\begin{tabular}{||c||c|c||}
\hline \hline Month & \%Landing & \%Take.Off \\
\hline \hline February & 98.5 & 97.4 \\
\hline April & 98.9 & 97.6 \\
\hline August & 99.2 & 98.2 \\
\hline \hline
\end{tabular}

TABLE VI

VALIDATION AIRPORT RUNWAY CONFIGURATION THROUGHT LVNL DATA

\section{CONCLUSIONS}

Optimal airport ground operations are key to reach the goals of the Single European Sky (SES) and the Next Generation Air Transportation System (NextGen) initiatives. In particular, aspects such as airport capacity, load noise and taxi times depend directly from a good management of the runways at the airports. Time flight and fuel optimization can also be improved having the historical runway usage/configuration.

The proposal of this work allows us to reconstruct that historical runway usage/configuration data in a massive manner. We have recovered successfully the information for different airports in Europe and we are confident that these methods can be applied worldwide. This opens the possibility to perform massive predictive analytics that enable dynamic adaptation to an ever changing environment. For instance, through machine learning techniques it can be generated models of prediction and optimization for airport operations.

\section{APPENDIX}

There are particular trajectories or location reports that cause conflicts to the algorithm described in this work. Even when we have this knowledge it becomes very difficult to correct these situations without compromising the overall performance that we have accomplished. Here, we summarize some of these cases to generate a thorough analysis of the weaknesses of the current version of the algorithm.

We have seen in Section III the good performance of the methodology after the consideration of the discarding tool included in the algorithm but the misassignment is the topic considered in this Appendix. Most of these errors are generated by the take-off maneuver. Figure 4 displays two trajectories that produce misclassification in the algorithm. Figure 4(A) describes a discarded trajectory when the assignment is correct, given the conditions over artificial angles. On the other hand, Figure 4(B) describes a not discarded wrong assessment given the optimal artificial angle that generates runway route 06 , when the true runway route is 09 .

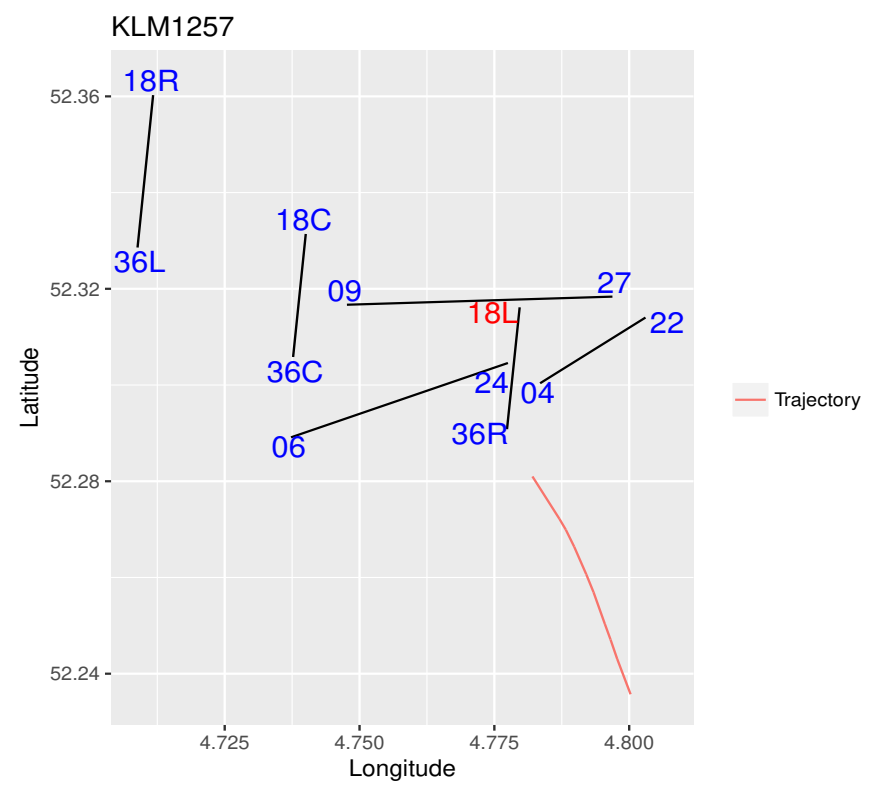

(A) Take-off using 09 route

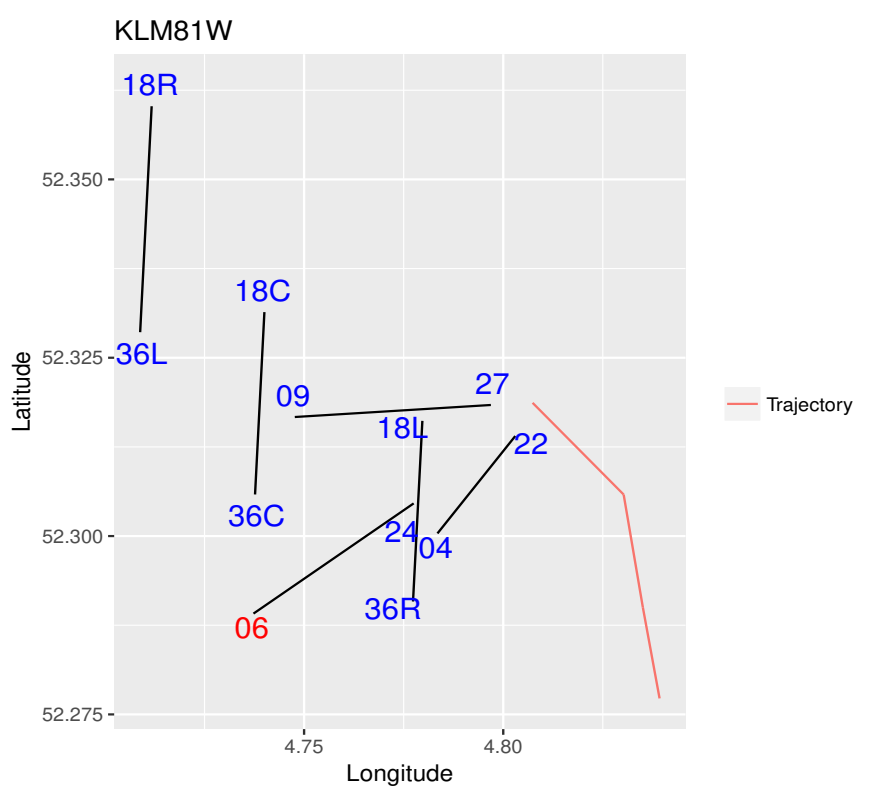

(B) Take-off using the $18 \mathrm{~L}$ route

Fig. 4. Examples of misclassifications

Another case of misclassification is shown in Figure 5, 
where is highly probable that a transmitting error generates the problems on this take-off trajectory. One can observe that the assessed runway label is label 22 when the true runway route is 24 , but the selection is due to the optimality conditions on the artificial angle. These special and bizarre cases are difficult to control and describe a latent error.

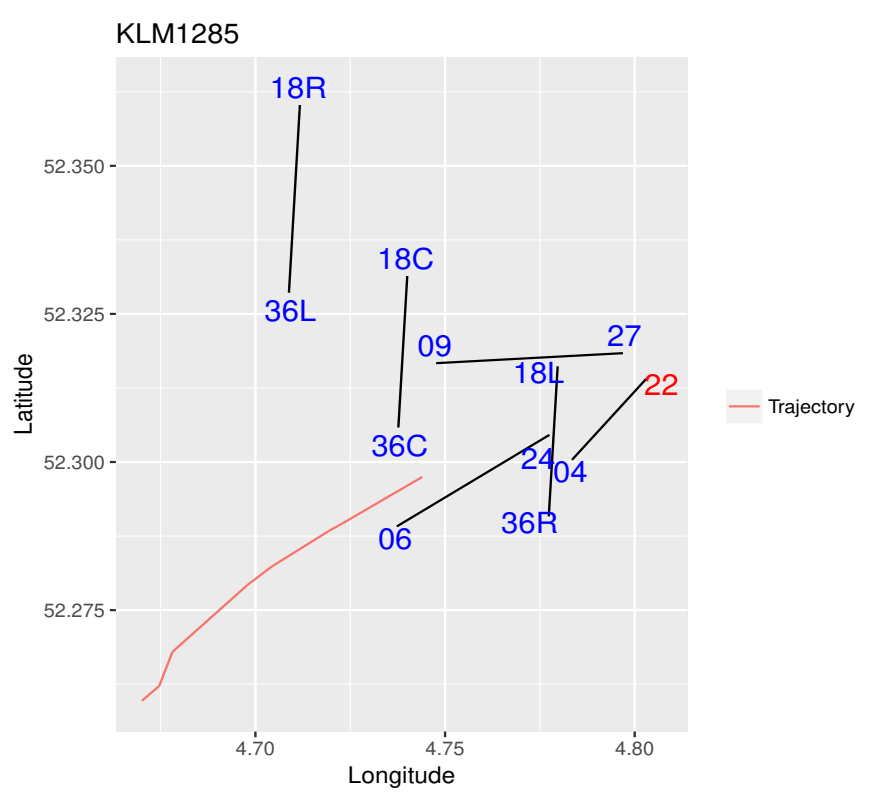

Fig. 5. Landing 06 route misclassification

\section{ACKNOWLEDGEMENTS}

This work is part of a joint project (AIRPORTS) with Boeing Research and Technology Europe (BRT\&E), and is funded by CDTI and MINECO (FEDER) ref. IDI-20150616, CIEN 2015. Authors are partly funded by MINECO (ref. MTM2017-86061-C2-1-P and MTM2017-86061-C2-2-P), and by Consejería de Educación de la JCyL and FEDER funds (ref. VA005P17 and VA002G18).

\section{REFERENCES}

[1] D. D. Group, “The World Bank: Air transport, passengers carried International Civil Aviation Organization, Civil Aviation Statistics of the World and ICAO staff estimates," https://data.worldbank.org/indicator/ IS.AIR.PSGR, 2018.

[2] Eurocontrol, "Eurocontrol Seven-Year Forecast. Flight Movements and Service Units 2019-2025," https://www.eurocontrol.int/publications/ seven-year-forecast-feb-2019, Eurocontrol, Tech. Rep., Feb. 2019.

[3] H. Balakrishnan and B. Chandran, "Algorithms for Scheduling Runway Operations Under Constrained Position Shifting," Operations Research, vol. 58, pp. 1650-1665, 2010.

[4] H. Lee and H. Balakrishnan, "A comparison of two optimization approaches for airport taxiway and runway scheduling." IEEE/AIAA 31st Digital Avionics Systems Conference (DASC), Williamsburg, Virginia, USA., 2012.

[5] H. Hesselink and J. Nibourg, "Probabilistic 2-Day Forecast of Runway Use." Ninth USA/Europe Air Traffic Management Research and Development Seminar (ATM2011), 2011.

[6] J. Avery and H. Balakrishnan, "Data-Driven Modeling and Prediction of the Process for Selecting Runway Configurations," Transportation Research Record: Journal of the Transportation Research Board, no. 2600 pp. 1-11, 2016, http://www.mit.edu/ hamsa/pubs/AveryBalakrishnan TRR2016.pdf.
[7] H. Hesselink, J. Nibourg, L. D’Estampes, and P. Lezaud, "Airport Capacity Forecast: Short-term forecasting of runway capacity," 4th SESAR Innovation Days, Nov 2014, Madrid, Spain. Proceedings of the SESAR Innovation Days, 2014.

[8] A. de Leege and C. Janssen, "Probabilistic Runway and Capacity Forecasting using Machine Learning to Support Decision Making," 6th SESAR Innovation Days, Nov 2016, Delft , Netherlands. Proceedings of the SESAR Innovation Days., 2016.

[9] R. J. Kennedy, "Four runway configuration types and their relation to arrival delays," Ph.D. dissertation, 2015.

[10] H. Lee, W. Malik, and Y. C. Jung, "Taxi-Out Time Prediction for Departures at Charlotte Airport Using Machine Learning Techniques." 16th AIAA Aviation Technology, Integration, and Operations Conference, AIAA AVIATION Forum, (AIAA 2016), 2016.

[11] D. Dhanasekaran, "Improved Prediction of Runway Usage for Noise Forecast," Master's thesis, 2014.

[12] M. A. Martínez-Prieto, A. Bregón, I. García-Miranda, P. C. ÁlvarezEsteban, F. Díaz, and D. Scarlatti, "Integrating flight-related information into a (Big) data lake." IEEE/AIAA 36th Digital Avionics Systems Conference (DASC), St. Petersburg, FL, USA, 2017, pp. 1-10, https://ieeexplore.ieee.org/document/8102023. 